\title{
Legal Considerations for Health Care Practitioners After Superstorm Sandy
}

Tina Batra Hershey, JD, MPH; Elizabeth Van Nostrand, JD; Rishi K. Sood, MPH; Margaret Potter, JD, MS

\section{ABSTRACT}

During disaster response and recovery, legal issues often arise related to the provision of health care services to affected residents. Superstorm Sandy led to the evacuation of many hospitals and other health care facilities and compromised the ability of health care practitioners to provide necessary primary care. This article highlights the challenges and legal concerns faced by health care practitioners in the aftermath of Sandy, which included limitations in scope of practice, difficulties with credentialing, lack of portability of practitioner licenses, and concerns regarding volunteer immunity and liability. Governmental and nongovernmental entities employed various strategies to address these concerns; however, legal barriers remained that posed challenges throughout the Superstorm Sandy response and recovery period. We suggest future approaches to address these legal considerations, including policies and legislation, additional waivers of law, and planning and coordination among multiple levels of governmental and nongovernmental organizations. (Disaster Med Public Health Preparedness. 2016;10:518-524)

Key Words: waivers of law, scope of practice, licensure, liability, Superstorm Sandy

S uperstorm Sandy struck New York City on October 29, 2012, causing the deaths of 43 New Yorkers and injuring or displacing tens of thousands. ${ }^{1}$ Access to health care was particularly affected, as many hospitals and other health care facilities were evacuated due to flooding and power failures. ${ }^{2}$ Health care practitioners in certain heavily impacted areas were faced with numerous challenges, including a compromised ability to provide necessary primary health care services. The effect on the overall health care system in New York City lingered for many months, with one hospital not reopening its inpatient ward until February 2013. ${ }^{3}$ Moreover, the operations of other health care entities were disturbed by Superstorm Sandy, including nursing homes, dialysis clinics, and opiate treatment programs. ${ }^{3}$

Legal issues contributed to the challenges faced by health care practitioners and facilities after Superstorm Sandy, because laws at the federal, state, and local level impact the delivery of health care services and must therefore be considered. Limitations in scope of practice for various practitioners, difficulties with credentialing for volunteers, lack of portability of practitioner licenses, and concerns regarding volunteer immunity and liability were contributory barriers to accessing primary care services. Waivers of law associated with declaration of emergencies issued by federal, state, and local officials alleviated some of these barriers, but others remained challenges to practitioners throughout the Superstorm Sandy response and recovery period.

This article highlights legal concerns faced by health care practitioners in the aftermath of Superstorm Sandy, as well as the strategies employed by governmental and nongovernmental entities that addressed some of these concerns. Because certain legal issues remained, we suggest future approaches to remove these remaining legal barriers to facilitate access to necessary health care services, including policies and legislation, additional waivers of law, and planning and coordination among multiple levels of government and nongovernmental organizations.

\section{LEGAL ISSUES FACED BY PRACTITIONERS Scope of Practice}

Scope of practice refers to the range of services that licensed health care practitioners, such as physicians, nurses, physician assistants, pharmacists, and emergency medical service (EMS) personnel, are authorized to perform. ${ }^{4}$ State practice laws and state regulating board rules govern which activities and procedures health care practitioners are allowed to perform, the amount of education and training required, and the level of required supervision or collaboration with a licensed physician or other health care practitioner. ${ }^{4,5}$

During and after a disaster, it may become necessary to modify the scope of practice for certain health care 
practitioners to meet increased demand for services. ${ }^{4,6}$ This modification can occur through the expansion of permitted activities or expansion of types of practitioners authorized to perform certain activities. It can also occur through removal of conditions related to medical control, supervision, documentation, education, and training. For example, a physician assistant may be permitted to provide certain services without the supervision of a physician. ${ }^{7}$ No standard procedure or approach exists regarding expansion of scopes of practice; therefore, states have taken different steps to fulfill health care needs after a disaster through expansion of scopes of practice. ${ }^{8}$

On October 26, 2012, New York Governor Andrew Cuomo issued a State Declaration of a Disaster Emergency for 62 counties in New York in anticipation of Superstorm Sandy. ${ }^{9}$ In accordance with New York law, the governor has the authority to initiate such a declaration by executive order when a disaster has occurred or is imminent and local governments are unable to respond to it adequately. ${ }^{10}$ Among other things, a declared emergency permits the governor to temporarily suspend or waive specific provisions of any statute, local law, ordinance, or an agency's regulation if compliance with the law would prevent, hinder, or delay action necessary to cope with the disaster. ${ }^{11}$ The suspension must be related to safeguarding the health and welfare of the public and must reflect a minimum deviation from the suspended provision. ${ }^{11}$

Governor Cuomo used this authority to issue several executive orders that modified scopes of practice in response to Superstorm Sandy. Under New York law in effect at the time of Sandy, pharmacists were limited to administering vaccinations for pneumococcal disease, influenza, and herpes zoster. ${ }^{12}$ In order to protect workers engaged in poststorm cleanup activities, ${ }^{13}$ pharmacists' scope of practice was expanded to include administration of the tetanus vaccine to adults in counties under federal emergency declaration under an order from a physician or certified nurse practitioner. ${ }^{14}$ This executive order provided similar permission to dentists and emergency medical technicians (EMTs); however, EMTs were subject to additional supervision requirements. ${ }^{14}$

Restrictions on lawfully prescribed controlled substances were relaxed after Superstorm Sandy. Licensed facilities, such as hospitals, nursing homes, and institutional dispensers, were permitted to temporarily accept, store, and administer controlled substances lawfully prescribed to patients and residents affected by Sandy, while maintaining appropriate patient-specific records and diversion-prevention practices. ${ }^{15}$ In addition, if pharmacists could verify the authenticity of a prescription through a shared database, they were permitted to dispense controlled substances to patients whose access to prescription medications was affected by Superstorm Sandy. ${ }^{15}$

\section{Licensure Portability}

Health care practitioners are licensed under state law. ${ }^{16}$ The ability of health care practitioners to cross state lines to provide care after disasters may become an issue when there is a medical surge due to this legal framework. ${ }^{6,17}$ Various mechanisms are in place to address licensure portability issues. One such mechanism is deployment of Disaster Medical Assistance Teams (DMATs) under the federal National Disaster Medical System (NDMS). DMATs are groups of professional and paraprofessional personnel who provide medical care during disasters and emergencies. ${ }^{18}$ When activated as federal employees under the NDMS, the licensure and certification of DMAT members is recognized by all states. ${ }^{18}$

The Emergency Management Assistance Compact (EMAC) is another mechanism that addresses licensure portability. The EMAC is an agreement among all states, the District of Columbia, and some US territories that provides for the interstate recognition of licenses held by professionals responding to disasters and emergencies. ${ }^{19}$ The EMAC has been utilized to deploy volunteers numerous times, including during the responses to Hurricanes Katrina and Rita. ${ }^{20}$ However, the EMAC mechanism has been criticized for being cumbersome and impeding the quick mobilization of private-sector volunteers. ${ }^{20}$

The Uniform Emergency Volunteer Health Practitioners Act (UEVHPA) was promulgated by the Uniform Law Commission in 2006 to respond to the lack of uniformity in state licensure laws for health care workers that was seen in the aftermath of Hurricane Katrina. ${ }^{21,22}$ The UEVHPA has been enacted by 14 states and 1 US territory, with legislation currently pending in 3 states. ${ }^{21}$ However, the law has not been passed in New York.

The UEVHPA provides a uniform process for quickly deploying health care practitioners during disasters and emergencies. ${ }^{22}$ Under the UEVHPA framework, health professionals register in advance of or during an emergency or disaster to provide volunteer services. ${ }^{21}$ Registration is accomplished by using either a governmentally established registration system, such as the Emergency System for Advanced Registration for Volunteer Health Professionals or Medical Reserve Corps (MRC), or through registration systems established by disaster relief organizations, state licensing boards, national or multi-state systems created by professional associations of licensing boards or health professionals, or other systems deemed to be qualified by a state. ${ }^{21,22}$ Health care facilities and disaster relief organizations may utilize these registered practitioners to deliver services to affected residents, confident that the registrants are licensed, qualified, and in good standing in the licensing state. ${ }^{22}$

Mutual aid agreements entered between jurisdictions are another way health care practitioners can practice across state lines. ${ }^{23}$ For example, Illinois law establishes the Interstate 
Mutual Emergency Aid Act that allows local governments to enter into mutual aid agreements with other local governments across state lines prior to a state or local emergency declaration. ${ }^{24}$ Thus, EMS personnel from other states may provide services in Illinois when requested as long as they are acting within the scope of their license, certification, or permit and within the scope of the Illinois-equivalent license, certificate, or permit. ${ }^{25}$

As with expansion of scopes of practice, executive orders were utilized to address licensure portability after Superstorm Sandy. Nurses not licensed in New York were permitted to provide nursing services to dialysis patients of a general hospital, nursing home, or diagnostic or treatment center licensed under New York law under certain conditions. ${ }^{26}$ These nurses were required to be in good standing in the licensing state and to be acting within their scope of practice. ${ }^{26}$ In addition, home health agencies not approved to operate in New York were authorized to provide services pursuant to a contract with the Federal Emergency Management Agency. ${ }^{27}$ The employees providing such home health care services were required to be licensed in good standing in another state and to be acting within their scope of practice. ${ }^{27}$ Despite these measures, licensure issues affected deployment of MRC volunteers during the Sandy response. Some MRC coordinators reported having to turn away volunteers not licensed in the state. ${ }^{28}$

Additional license portability for nurses is offered in states that have adopted the Nurse Licensure Compact (NLC). The NLC allows nurses to have one multistate license that allows them to practice in both their home state and other compact states. ${ }^{29}$ Nurses practicing under the NLC are subject to the laws and regulations of the state in which the patient is located. Thus, adoption of the NLC will permit nurses from surrounding states to provide nursing services in a disasteraffected state without a declaration of emergency and waiver of nursing laws. New York is not one of the 24 states currently participating in the NLC, although legislation is pending. ${ }^{29}$

Other health care practitioner groups are proposing compacts to address licensure portability. For example, the National Association of State EMS Officials has developed the "Recognition of EMS Personnel Licensure Interstate CompACT," REPLICA, which would allow EMS personnel licensed in a state that had adopted REPLICA to operate as EMS personnel in other REPLICA-member states. ${ }^{30}$ Two states, Colorado and Texas, have enacted legislation that adopts REPLICA, and several other states have proposed enacting legislation. REPLICA will go into effect after 10 states enact REPLICA-enabling statutes. ${ }^{30}$

\section{Credentialing of Volunteer Health Care Practitioners}

Credentialing of volunteer health care practitioners is another important consideration following a disaster, as facilities may augment their staff to address medical surge that exceeds their staffing capacities. ${ }^{31}$ The process of credentialing and privileging, during which the licensing, education, and experience of practitioners is reviewed, is an important component that ensures that quality care is provided by licensed practitioners in good standing. ${ }^{32}$ However, this process is time-consuming and may not be practical after a disaster when there is a medical surge and numerous patients seeking care. ${ }^{31}$ To address this surge, some facilities have established a process to grant expedited disaster privileges when "exceptional circumstances exist," meaning any situation in which delay of deployment of volunteer practitioners may cause exacerbation of illness or injury and/or death of patients at the facility. ${ }^{33}$ Indeed, in June 2012, the Iroquois Healthcare Association and the Healthcare Association of New York State collaboratively created a volunteer management tool for facilities called "Integrating Emergency Volunteers During Medical Surge" that contains a checklist, guidelines, template policies and procedures, and an emergency volunteer privileges application. ${ }^{33}$ Under this tool, the decision to credential and privilege is decided at the discretion of the facility administrator on a case-by-case basis. The volunteer practitioner is subject to oversight of the volunteer's professional competence and the disaster privileges are effective only for the length of the disaster.

After Superstorm Sandy struck New York City, operations at numerous hospitals and health care facilities were significantly disrupted, leaving many health care practitioners with no place to practice. $^{2}$ Some facilities used these displaced health care practitioners to address medical surge, thereby necessitating verification of the credentials of these health professionals. ${ }^{34,35}$ A study of the effect of hospital evacuations after Sandy on New York City's health system found variation in the credentialing processes of hospitals receiving evacuees. ${ }^{35}$ One hospital expedited credentialing of physicians from an evacuated hospital, while another hospital followed its customary process a little more quickly. ${ }^{35}$

\section{Immunity and Liability Concerns}

Shielding medical personnel, public health practitioners, volunteers, and others from liability during disaster response is essential to ensure the adequate delivery of emergency services. Fear of liability may prevent or delay deployment of volunteers. ${ }^{20,31,34,36}$ Various protections are available at the federal, state, and local level; in general, coverage is highly dependent on the function emergency personnel are performing. These laws, which are summarized in Table 1, can be confusing ${ }^{31,36}$ and have not been well vetted before the judiciary.

At the federal level, the Volunteer Protection Act of 1997 protects volunteers who are properly licensed or certified or 


\begin{tabular}{|c|c|c|}
\hline Law & Individuals Protected & Exemptions \\
\hline Volunteer Protection Act of 1997 & $\begin{array}{l}\text { - Properly licensed or certified volunteers } \\
\text { (medical and nonmedical volunteers of } \\
\text { nonprofit organizations) acting within the } \\
\text { scope of employment } \\
\text { - Does not apply to organization }\end{array}$ & $\begin{array}{l}\text { - Willful or wanton misconduct } \\
\text { - Gross negligence } \\
\text { - Reckless misconduct } \\
\text { - Flagrant indifference to the injured individual }\end{array}$ \\
\hline $\begin{array}{l}\text { Emergency Management } \\
\text { Assistance Compact }\end{array}$ & $\begin{array}{l}\text { - Assisting state } \\
\text { - State officers } \\
\text { - State employees }\end{array}$ & $\begin{array}{l}\text { - Willful misconduct } \\
\text { - Gross negligence } \\
\text { - Recklessness }\end{array}$ \\
\hline $\begin{array}{l}\text { New York State Laws Pertaining } \\
\text { to Volunteers }\end{array}$ & $\begin{array}{l}\text { - ServNY volunteers acting within their scope of } \\
\text { public employment }\end{array}$ & $\begin{array}{l}\text { - Intentional wrongdoing } \\
\text { - Must also use individual liability insurance }\end{array}$ \\
\hline $\begin{array}{l}\text { New York City laws pertaining } \\
\text { to volunteers }\end{array}$ & $\begin{array}{l}\text { - NYC Medical Reserve Corps volunteers acting } \\
\text { within the scope of employment }\end{array}$ & - Violations of agency rules or regulations \\
\hline New York Good Samaritan Law & $\begin{array}{l}\text { - Licensed health care professionals while } \\
\text { rendering assistance during emergencies }\end{array}$ & $\begin{array}{l}\text { - Gross negligence } \\
\text { - Treatment in the normal and ordinary course } \\
\text { of practice }\end{array}$ \\
\hline
\end{tabular}

otherwise authorized to perform a certain action from liability when they perform such action within the scope of their responsibilities. ${ }^{37}$ Volunteers are defined as individuals who do not receive compensation or anything else of value exceeding $\$ 500$ per year in lieu of compensation for services. $^{37}$ The Volunteer Protection Act, which preempts state laws that provide lesser protection, applies to both medical and nonmedical volunteers of nonprofit organizations or governmental entities, but not to the entity itself. There is no protection from "willful or wanton misconduct, gross negligence, reckless misconduct, or a conscious, flagrant indifference to the rights or safety of the individual harmed by the volunteer." 37 Certain volunteers, such as DMAT members, are covered under the Federal Tort Claims Act if they are deemed to be federal employees. ${ }^{38}$ In these cases, when litigation ensues, the federal government becomes the defendant in any malpractice action.

EMAC provides some liability protections as well. If EMAC is activated, no assisting state, state officer, or employee of the state rendering aid will be liable for an act or omission that occurs in good faith. ${ }^{19}$ Exceptions are made for willful misconduct (which are intentional actions), gross negligence (actions that often involve the deliberate disregard of another individual's safety), or recklessness (incidents where an individual knew or should have known were likely to cause harm). However, EMAC applies only to state government employees and those deemed to be state employees. ${ }^{39,40}$ Many health care practitioners may, therefore, not be immune from liability under EMAC. $^{39,40}$
New York law also addresses liability and immunity concerns. Volunteers with ServNY, which is New York State's MRC, are indemnified under New York law if they are acting within the scope of public employment; however, the duty to indemnify does not arise if the injury or damage was as a result of intentional wrongdoing. ${ }^{41}$ In addition, if the volunteer has other liability insurance, the individual must use it in addition to the state's coverage. ${ }^{41}$

Members of the New York City MRC, which is ServNY's counterpart in New York City, are considered to be an extension of New York City's workforce and are indemnified accordingly. ${ }^{42}$ For an action to be covered under this indemnity provision, 2 criteria must be met: (1) the individual must have acted within the scope of his or her employment and (2) the individual's conduct cannot be in violation of an agency rule or regulation. ${ }^{42}$ Immunity provided under any federal, state, or local law is not affected by the use of this provision. ${ }^{42}$

New York also has a Good Samaritan law. ${ }^{43}$ Generally, Good Samaritan laws protect licensed health care professionals, such as physicians, nurses, and physician assistants, from civil liability for acts or omissions that cause injury to another while rendering assistance during emergencies. ${ }^{43}$ Good Samaritan laws mostly apply to individuals who provide care in emergencies rather than to organized volunteer groups. Such laws are affirmative defenses rather than a legal grant of immunity. They do not cover individuals who are grossly negligent nor when care or treatment is rendered in the normal and ordinary course of the individual's practice. 


\section{DISCUSSION}

Legal considerations can be a barrier to the ability of health care facilities and health care practitioners to provide necessary health care services after a disaster. In the aftermath of Superstorm Sandy, various strategies were used to address these legal concerns; still, legal barriers remained related to scope of practice, licensure portability, credentialing, and liability protections for volunteers. However, through planning and coordination, many of these remaining legal issues can be addressed prior to a disaster so that necessary care can be provided without delay. These planning efforts are most effective when they are coordinated between multiple levels of government and nongovernmental organizations.

Issues related to scope of practice may be addressed by a broader use of executive orders to expand scopes of practice after a disaster. For example, the supervision requirements related to physician assistants in office settings could be relaxed to allow physician assistants to provide additional primary care services. In addition, pharmacists could be permitted to administer additional vaccines, as well as to vaccinate pediatric patients in certain situations. Accordingly, government officials may wish to consider issuing additional executive orders or using other mechanisms to provide for broader scope of practice expansion in future disaster recovery periods. Having such orders or directives ready in advance of a disaster will allow for careful crafting to ensure that all necessary categories of providers have their scope of practice broadened.

Additional executive orders or similar policy mechanisms may be used to address licensure portability to allow more health care practitioners to cross state lines to provide the health care services that are needed after a disaster. As the need for volunteer health care practitioners may extend beyond the response period well into the recovery phase, licensure portability policy mechanisms should address both short-term and longer term considerations, including when the presence of out-of-state volunteers is no longer beneficial to the overall health system. ${ }^{44}$

Further, the adoption of legislation may alleviate issues related to licensure portability. The UEVHPA framework would allow health care practitioners from other states to offer their services to New York residents affected by disasters. Similarly, the NLC would permit nurses from surrounding states to provide nursing services in the aftermath of a disaster. Pending legislation in New York proposes to adopt the NLC; thus, government officials are aware of the need to address licensure portability concerns in both disaster and nondisaster situations.

In addition to government, other entities must plan for legal considerations that may arise during and after a disaster. Hospitals and other health care facilities can address legal issues in advance by ensuring that they have streamlined emergency credentialing procedures and adopted policies and procedures to incorporate volunteer health care practitioners after disasters. Hospitals and other health care institutions should also consider issues related to sterilization of instruments and maintenance of equipment during and after disasters, and associated personnel issues, in order to protect patient safety as well as shield themselves from liability. Moreover, drills related to disaster privileging can help facilities practice so that they are fully prepared before the next disaster strikes. Physician practices may also wish to consider advance planning for disaster-related issues.

Volunteers at hospitals and in other settings often find themselves confused by the potpourri of available immunity and liability protections. ${ }^{45}$ Indeed, during the Superstorm Sandy response and recovery period, local health department staff reported that "many MRC volunteers did not want to deploy to shelters without having a clearly defined understanding of liability coverage. ${ }^{28}$ In addition, a local MRC coordinator turned away medical volunteers due to liability concerns. ${ }^{28}$ Thus, communicating liability and immunity protections to volunteers in a clear and concise manner is critical to rapid volunteer deployment. Additional guidance documents, written in laypersons terms, may prove helpful to these volunteer practitioners.

In New York after Superstorm Sandy, preparedness within the legal framework we described permitted officials to suspend various requirements to allow for improved access to both health care providers and prescription medications. For example, guidance issued by the New York State Board of Pharmacy and the suspension of certain laws to permit pharmacists to dispense medications in certain circumstances while using their professional judgement allowed patients to access prescription drugs that would have otherwise been unavailable. ${ }^{15,46}$ These measures, which were possible due to the preparation of New York State officials before the disaster, assisted in ensuring access to health care and needed medications to those directly affected by the disaster.

Further, in 2010, the New York State Legislature created the Intrastate Mutual Aid Program to provide mutual assistance among local governments to assist in preventing, responding to, or recovering from disasters. ${ }^{47}$ This legislation allows for greater coordination between local governments and assists in streamlining the sharing of resources as needed under the formal declaration of an emergency. The Intrastate Mutual Aid Program in New York is an example of a mechanism to reduce legal barriers to effective disaster recovery.

\section{CONCLUSION}

Health care practitioners faced a myriad of legal considerations while providing care to affected residents after Superstorm Sandy, including limitations in scope of practice for various practitioners, difficulties with credentialing for volunteers, lack of portability of practitioner licenses, and concerns regarding volunteer immunity and liability. The 
response from federal, state, and local governments after Superstorm Sandy included various actions to address these concerns, such as waivers of law and associated executive orders. Many of these actions, and the deployment of mobile health clinics by various organizations that provided more than 4000 visits in the months following Sandy, ${ }^{1}$ can be credited with preventing an extended health care access deficit after Sandy. However, legal barriers affecting health care practitioners still remained, impacting the provision of care by health care practitioners. Effective planning, including addressing the legal considerations enumerated above, will help decision-makers develop and implement policies and interventions to reduce access deficits in populations at risk for disasters and lead to improved preparedness, response, and recovery efforts in our health care system.

\section{About the Authors}

Department of Health Policy and Management, Graduate School of Public Health, University of Pittsburgh, Pittsburgh, Pennsylvania (Profs Hershey, Van Nostrand, and Potter), and the Bureau of Primary Care Access and Planning, New York City Department of Health and Mental Hygiene, Long Island City, New York (Mr Sood).

Correspondence and reprint requests to Tina Batra Hershey, JD, MPH, Department of Health Policy and Management, Graduate School of Public Health, University of Pittsburgh, 130 DeSoto St, A746 Crabtree, Pittsburgh, PA 15261 (e-mail: tbh16@pitt.edu).

\section{Acknowledgments}

We thank Supriya Kumar, PhD, MPH, Department of Behavioral and Community Health Sciences, Graduate School of Public Health, University of Pittsburgh, and Hasan Guclu, PhD, Department of Health Policy and Management, Graduate School of Public Health, University of Pittsburgh, for their helpful comments.

\section{Funding}

Funded through the University of Pittsburgh Center for Public Health Practice by The Assistant Secretary for Preparedness and Response Project Number 1 HITEP130004-01-00.

\section{Disclaimer}

The opinions, results, findings and/or interpretations of data contained herein are solely the responsibility of the authors and do not represent the opinions, interpretation, or policy of the Assistant Secretary for Preparedness and Response, the University of Pittsburgh, the New York City Department of Health and Mental Hygiene, or the City of New York.

Published online: March 29, 2016.

\section{REFERENCES}

1. Gibbs L, Holloway C. Hurricane Sandy After Action: Report and Recommendations to Mayor Michael R. Bloomberg. http://www.nyc. gov/html/recovery/downloads/pdf/sandy_aar_5.2.13.pdf. Published May 2013. Accessed November 17, 2015.

2. Powell T, Hanfling D, Gostin LO. Emergency preparedness and public health: the lessons of Hurricane Sandy. JAMA. 2012;308(24):2569-2570.

3. Teperman S. Hurricane Sandy and the greater New York health care system. J Trauma Acute Care Surg. 2013;74(6):1401-1410.

4. Courtney B, Morhard R, Bouri N, et al. Expanding practitioner scopes of practice during public health emergencies: experiences from the 2009
H1N1 pandemic vaccination efforts. Biosecur Bioterror. 2010;8(3): 223-231.

5. NY Educ Law title VIII, articles 131 (physicians), 131-B (physician assistants), and 139 (nurses).

6. Catlett CL, Jenkins JL, Millin MG. Role of emergency medical services in disaster response: resource document for the National Association of EMS Physicians position statement. Prehosp Emerg Care. 2011; 15(3):420-425.

7. AZ Rev Stat $\$ 32-2535$.

8. Courtney B. Five legal preparedness challenges for responding to future public health emergencies. J Law Med Ethics. 2011;39:60-64.

9. NY Exec Order No. 47 (October 26, 2012).

10. NY CLS Exec $\S 28$.

11. NY CLS Exec $\$ 29$-a.

12. NY CLS Educ $§ 6802 ; 8$ NYCRR $§ 63.9$.

13. Press release: Governor Cuomo signs executive order to allow pharmacists, EMTS, and dentists to help administer tetanus vaccines in areas affected by Hurricane Sandy. https://www.governor.ny.gov/news/governor-cuomosigns-executive-order-allow-pharmacists-emts-and-dentists-help-admin ister. Published November 10, 2012. Accessed November 17, 2015.

14. NY Exec Order No. 68 (November 9, 2012).

15. NY Exec Order No. 72 (November 11, 2012).

16. Gostin LO, Koplan JP, Grad FP. The law and the public's health: the foundations. In: Goodman RA, Hoffman RE, Lopez W. et al, eds. Law in Public Health Practice. 2nd ed. New York, NY: Oxford, University Press; 2007:25-44

17. Sherman SE. Legal considerations in a nuclear detonation. Disaster Med Public Health Prep. 2011;5:S65-S72.

18. US Department of Health and Human Services, Office of the Assistant Secretary for Preparedness and Response. Disaster Medical Assistance Team. http://www.phe.gov/preparedness/responders/ndms/teams/pages/ dmat.aspx. Accessed February 4, 2016.

19. Emergency Management Assistance Compact. PL 104-321 (1996).

20. Hodge JG. Legal issues concerning volunteer health professionals and the hurricane-related emergencies in the Gulf Coast region. Public Health Rep. 2006;121(2):205-207.

21. Emergency Volunteer Health Practitioners. Uniform Law Commission website. http://www.uniformlaws.org/Act.aspx?title=Emergency\%20Volun teer\%20Health\%20Practitioners. Accessed March 4, 2016.

22. Hodge JG, Pepe RP, Henning WH. Voluntarism in the wake of Hurricane Katrina: the uniform emergency volunteer health practitioners act. Disaster Med Public Health Prep. 2007;1(1):44-50.

23. Emergency Medical Services and Medical Surge: Essential Legal Issues. Oak Ridge Associated Universities. http://orau.gov/hsc/emslegalwebinar/ downloads/EMS-LegallssuesReport.pdf. Accessed January 28, 2016.

24. 5 ILCS $235 / 10$.

25. 5 ILCS 235/15.

26. NY Exec Order No. 57 (November 2, 2012).

27. NY Exec Order No. 64 (November 5, 2012).

28. US Department of Health and Human Services Office of Inspector General. Medical Reserve Corp volunteers in New York and New Jersey during Superstorm Sandy. http://oig.hhs.gov/oei/reports/oei-04-1300350.pdf. Published May 2015. Accessed November 19, 2015.

29. Nurse Licensure Compact. National Council of State Boards of Nursing website. https://www.ncsbn.org/nurse-licensure-compact.htm. Accessed March 4, 2016.

30. National Association of State EMS Officials. Recognition of EMS Personnel Licensure. https://www.nasemso.org/Projects/REPLICA/ documents/REPLICA-Final-Model-Sept2014.pdf. Published September 2014. Accessed January 28, 2016.

31. Hodge JG, Gable LA, Calves SH. Volunteer health professionals and emergencies: assessing and transforming the legal environment. Biosecur Bioterror. 2005;3(3):216-223.

32. Showalter JS. Medical staff privileges and peer review. In: Showalter JS. The Law of Healthcare Administration. Chicago: Health Administration Press; 2015:243-290. 
33. Integrating Emergency Volunteers During Medical Surge. Iroquois Health Association and Healthcare Association of New York State. http://www. hanys.org/emergency/planning/docs/integrating_emergency_volunteers_ checklist.pdf. Published June 2012. Accessed October 30, 2015.

34. VanDevanter N, Kovner CT, Raveis VH, et al. Challenges to nurses' deployment to other New York City hospitals in the aftermath of Hurricane Sandy. J Urban Health. 2014;91(4):603-614.

35. Adalja AA, Watson M, Bouri N, et al. Absorbing citywide patient surge during Hurricane Sandy: a case study in accommodating multiple hospital evacuations. Ann Emerg Med. 2014;64(1):66-73.

36. Hoffman S, Goodman RA, Stier DD. Law, liability, and public health emergencies. Disaster Med Public Health Prep. 2009;3(2):117-125.

37. 42 U.S.C. $\$ 14501$, et seq.

38. 28 U.S.C $\$ 1346(b)$.

39. Hodge JG Jr. Assessing the legal environment concerning mass casualty event planning and response. In: Phillips SJ, Knebel AR, ed. Mass Medical Care with Scarce Resources: A Community Guide. AHRQ publication no. 070001. Rockville, MD: Agency for Healthcare Research and Quality; 2007.

40. Allen DC, Harris SF. Licensure issues in the event of a disaster or emergency. American Health Lawyers Association Emergency Preparedness
Toolkit. https://www.healthlawyers.org/Members/PracticeGroups/THAMC/ EmergencyPreparednessToolkit/Documents/IX_Licensure/B_Licensur eIssuesDuringDisasterEmergency.pdf. Accessed October 30, 2015.

41. NY CLS Pub O $\$ 17$.

42. NY CLS Gen Mun $\S 50-k$.

43. NY CLS Pub Health $\S 3000$-a.

44. Committee on Post-Disaster Recovery of a Community's Public Health, Medical, and Social Services; Board on Health Sciences Policy; Institute of Medicine. Healthy, Resilient, and Sustainable Communities After Disasters: Strategies, Opportunities, and Planning for Recovery. Washington, DC: National Academies Press; 2015. http://www.ncbi.nlm.nih.gov/books/NBK316524/. Accessed February $1,2016$.

45. Williams M, Trued S, Duggan B, et al. Examining New York City hospitals' nonuse of medical volunteers in disasters. Disaster Med Public Health Prep. 2015;9(4):391-395.

46. New York Education Department. New York State Board of Pharmacy. Emergency Access to Prescription Medications. https://www.iapsrx.org/ news.html/65. November 1, 2012. Accessed February 4, 2016.

47. NY CLS Exec § 29-h. 